\title{
Hydrogen Peroxide Skull Base Specimen Preparation: Singular View of Hidden Topographic Anatomy
}

\author{
Michaela DEDECIUSOVÁ ${ }^{1,2}$, Louis-Marie TERRIER ${ }^{3,4}$, David NETUKA' ${ }^{1,2}$, Vladimír BENEŠ ${ }^{1,2}$, Stéphane VELUT ${ }^{3,4}$ \\ ${ }^{1}$ Military University Hospital Prague, Department of Neurosurgery and Neurooncology, The Czech Republic \\ ${ }^{2}$ Charles University in Prague, First Faculty of Medicine, Prague, The Czech Republic \\ ${ }^{3}$ INSERM, Imagerie et cerveau UMR U1253, Université de Tours, Tours, France \\ ${ }^{4}$ Service de Neurochirurgie, CHRU de Tours, Hôpital Bretonneau, 2, Boulevard Tonnellé, 37044 Tours Cedex 9, France
}

Corresponding author: Michaela DEDECIUSOVÁ michaela.dedeciusova@seznam.cz

\section{ABSTRACT}

\begin{abstract}
AIM: To present the technical principles of the hydrogen peroxide head preparation method, and to demonstrate the high quality of
\end{abstract} anatomical studies performed using these specimens, particularly for arachnoid exploration.

MATERIAL and METHODS: Five cadaveric heads were set with a 10\% formalin solution and then injected with coloured latex. Thereafter, the heads were bleached with hydrogen peroxide solution $20 \%$. Anatomical dissection of all specimens was performed. The skull base was drilled, dura mater gradually resected and outer arachnoid membranes examined and opened. The topographical anatomy was studied.

RESULTS: All soft tissues, the brain, cranial nerves, the vasculature, the dura mater and even the arachnoid, were macroscopically intact, which enabled high-quality skull base specimens. In addition, the bone was softened, facilitating the drilling process. The topographical anatomy of anterior clinoid process was selected as an example and depicted in photos.

CONCLUSION: High-quality anatomical specimens were obtained using the hydrogen peroxide head preparation. The topographic anatomy was studied from a unique downside-up angle, as well as by following the passage of the key neurovascular structures during its course. We propose the use of this method in neurosurgical training, especially to practice extradural approaches. Moreover this method seems promising as a complementary method for arachnoid studies.

KEYWORDS: Head embalming, Neuroanatomy, Skull base, Cadaveric study, Arachnoid membrane

ABBREVIATIONS: HPHP: Hydrogen peroxide head preparation, HPS: Hydrogen peroxide solution, ACP: Anterior clinoid process, SOF: Superior orbital fissure, OC: Optic canal, OS: Optic strut, ONs: Optic nerves, ICA: Internal carotid artery, CS: Cavernous sinus

\section{INTRODUCTION}

$\mathrm{T}$ The technical principles of hydrogen peroxide head preparation (HPHP) technique to obtain skull base specimens were recently published (3). This technique allows for macroscopic and microscopic preservation of the brain, arachnoid and dura mater while the bone is considerably softened because of decalcification obtained by corrosive chemicals present in the hydrogen peroxide solution (HPS) (3).
The aim of this article is to demonstrate the high-quality of skull base specimens acquired using HPHP technique. The regional topographic anatomy of the anterior clinoid process (ACP) was selected as an example. It is reviewed in stepwise fashion, similarly to the dissection performed from the superficial to the deeper structures.

Two possible fields of application of the skull base specimens acquired by HPHP technique are suggested. First, the
Michaela DEDECIUSOVÁ (D: : 0000-0002-2709-6159

Louis-Marie TERRIER (D) : 0000-0003-3445-7773

David NETUKA
Vladimír BENEŠ (D): 0000-0002-6889-857X

Stéphane VELUT (D) : 0000-0002-8961-5081 
dissection of specimens prepared by the HPHP technique could be included in basic neurosurgical training. It allows for learning topographic skull base anatomy and it is especially suitable for learning or even planning extradural microscopic or endoscopic approaches. Second, it is a unique method that allows for observation of the arachnoid cisterns and should be a complementary method for arachnoid studies.

\section{MATERIAL and METHODS}

\section{Experimental Protocol}

Five adult cadaveric heads were obtained from the body donation program of the University of Tours, France. The following sequence of steps was performed (3):

1. Vascular injection: Red latex was injected in the internal carotid and vertebral arteries and blue latex in the jugular veins.

2. Exposure of the external skull base and convexity: All soft tissue, the mandible and the maxilla were removed and the sphenoid sinus exposed anteriorly through a large opening.

3. Specimens were set with a $10 \%$ formalin solution for 1 week: small craniotomies with dural opening were performed on the coronal suture to expose the brain.

4. Exposition to the HPS for 3 weeks: the specimens were subsequently bleached with HPS $20 \%$ added to the $10 \%$ formalin solution.

5. Baths were renewed weekly.

6. Dissections were performed using an operative microscope (Leica M500-N ${ }^{\circledR}$ ). Skull base was removed using the Anspach high-speed drill system or rongeur. For this purpose the specimens were turned downside up to allow an uncommon inferior view. Dura mater was opened and resected. The outer arachnoid membrane was opened. Photos were taken using the Canon EOS 80D ${ }^{\circledR}$ camera.

\section{RESULTS}

All specimens were macroscopically intact after a 3-week exposition to the HPS. All vessels, cranial nerves, brain, arachnoid and dura mater appeared unchanged. However, the skull base was softened, which made the drilling was considerably faster. We noted less adherence between the skull base and the dura. Moreover, the arachnoid stays translucent and seems to be preserved better than using the standard formalin fixed cadavers.

\section{Step-wise Regional Topographic Anatomy: The Anterior Clinoid Process}

The complex osseous anatomy of the skull base is best understood by its consecutive drilling. The position and topographical relationships of the ACP are displayed in Figure 1. Gradually, three parts of ACP base are drilled: 1) lesser wing - forming the roof of the superior orbital fissure (SOF) laterally, 2) anterior root - forming the roof of the optic canal
(OC) supero-medially and 3) posterior root - the optic strut (OS) infero-medially (18).

Following complete removal of the skull base the external dural surface is observed, as depicted in Figure 1A. Dura mater covering: the optic nerves (ONs) passing through the OCs, the clinoidal and cavernous segments of the internal carotid artery (ICA) in cavernous sinus (CS) and the pituitary gland in the sella turcica. Further dissection allows for the topographic study of the CS. The view of its content after medial wall resection is shown in Figure 1B. For instance, the passage of the abducens nerve from the prepontine cistern through Dorello's canal to the lateral aspect of the intracavernous segment of the ICA is visualised.

Following the removal of the dura mater, the outer arachnoid membrane forming a clear strong envelope around the brain is observed. At the central skull base, as showed in Figure 2A, it forms the floor of carotid and chiasmatic cisterns, covers the ONs within the OCs and extends into the intrasellar region forming the subdiaphragmatic extension of the chiasmatic cistern (11). There are 13 inner arachnoid membranes in anterior and middle cranial fossae (11). In Figure 2B, the arachnoid membranes surrounding the ACP are showed. Medially, the medial carotid membrane forms the border between the carotid and chiasmatic cistern. Posteriorly, the diencephalic leaf of the Liliequist's membrane complex, forms the border between the chiasmatic and the interpeduncular cistern. This membrane is laterally continuous with the temporal membrane. Posteriorly, the lateral carotid membrane stretches between the superomedial surface of the uncus and the crus cerebri $(11,12)$.

The outer arachnoid membranes are incised allowing observation of the arachnoid cisterns with its content, depicted in Figure 2B. The chiasmatic cistern contains the optic chiasm and ONs, the pituitary stalk and small ICA branches to these structures. The ophthalmic artery enters this cistern within the OC $(25,26)$. The ON and ophthalmic artery continue to the OC superomedially to the OS $(6,18,20,22)$. The carotid cistern contains the supraclinoidal portion of ICA, the origins of ophthalmic, posterior communicating and anterior choroidal arteries, small arteries to the ONs and pituitary stalk, and variably frontoorbital veins $(25,26)$. The clinoidal segment of the ICA grooves the postero-infero-medial aspect of the ACP at the point of its attachment by the OS (20).

\section{DISCUSSION}

Commonly used decalcification agents (EDTA, formic acid, acetate acid) are aggressive and linked to an increased risk of brain tissue destruction $(1,19)$. However, the HPHP technique seems to overcome this problem. The decalcification is caused by the corrosive effect of hydrogen peroxide, which enables macroscopic preservation of the soft tissues (3). The technical aspects including macroscopic, histologic, radiologic study and calcium concentration measurement were published previously (3). The aim of this article is to demonstrate its potential to undertake high-quality skullbase specimens. We suggest its implication in neurosurgical training, e.g.extradural 
microscopic and endoscopic approaches, and in anatomical arachnoid studies.

\section{Regional Topographic Anatomy and Extradural Approaches}

The softened skull base could be drilled or even removed by the Kerrison rongeur inconsiderably less time compared with non-softened anatomical specimens. Moreover, the unusual direction of dissection - inferior to superior and exterior to interior -permits the singular views of topographic anatomy as represented in Figures $1 \mathrm{~A}, \mathrm{~B}$ and $2 \mathrm{~A}, \mathrm{~B}$. Our anatomical observation differ from classical anatomical studies (e.g. extracted brain, superior view of osseous skull base) and even more from surgical views when only a narrow corridor is drilled. The method could be especially useful in learning or even designing the microscopic and endoscopic extradural approaches. For instance, the position and orientation of the $\mathrm{OS}$ is difficult to understand as this bony pillar lies beyond the ACP $(6,10)$. As a consequence its drilling is the major pitfall of extradural anterior clinoidectomy. The inferior view in Figure $1 \mathrm{~A}, \mathrm{~B}$, helps to understand the OS position and topography properly, with the ON located superomedially and the ICA located inferoposteriorly (22).
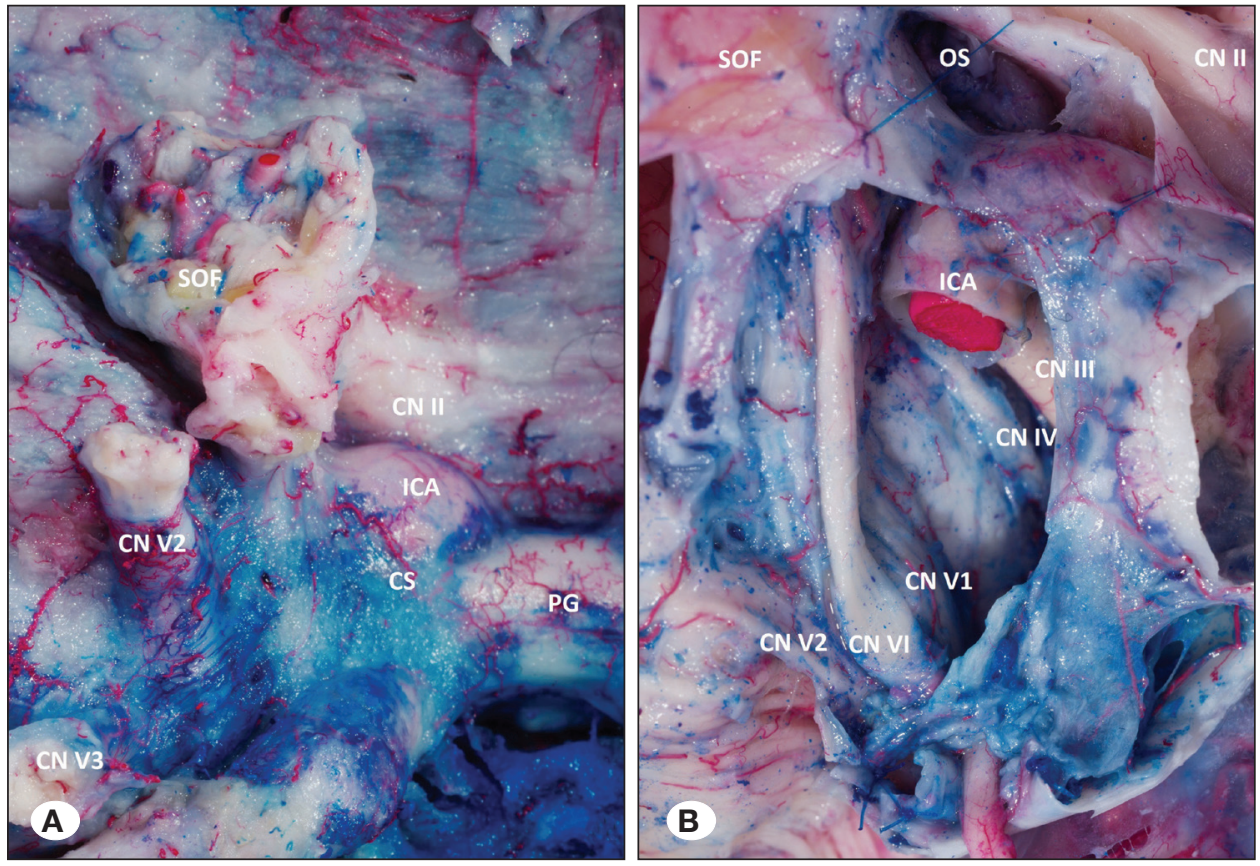

Figure 1: Dural anatomy.

A) Outer dural surface. SOF: Superior orbital fissure, CS: Cavernous sinus; CN II: optic nerve in the optic canal, CN V2: the maxillary division of the trigeminal nerve, CN V3: the mandibular division of the trigeminal nerve, ICA: cavernous segment of the internal carotid artery,

PG: pituitary gland.

B) The view of the CS after medial wall resection. SOF: Superior orbital fissure, OS: position of the optic strut, CN II: optic nerve in the optic canal,

CN III: oculomotor nerve,

CN IV: trochlear nerve,

CN V1: ophthalmic division of the trigeminal nerve, CN V2: the maxillary division of the trigeminal nerve,

CN VI: abducens nerve,

ICA: cavernous segment of the internal carotid artery.
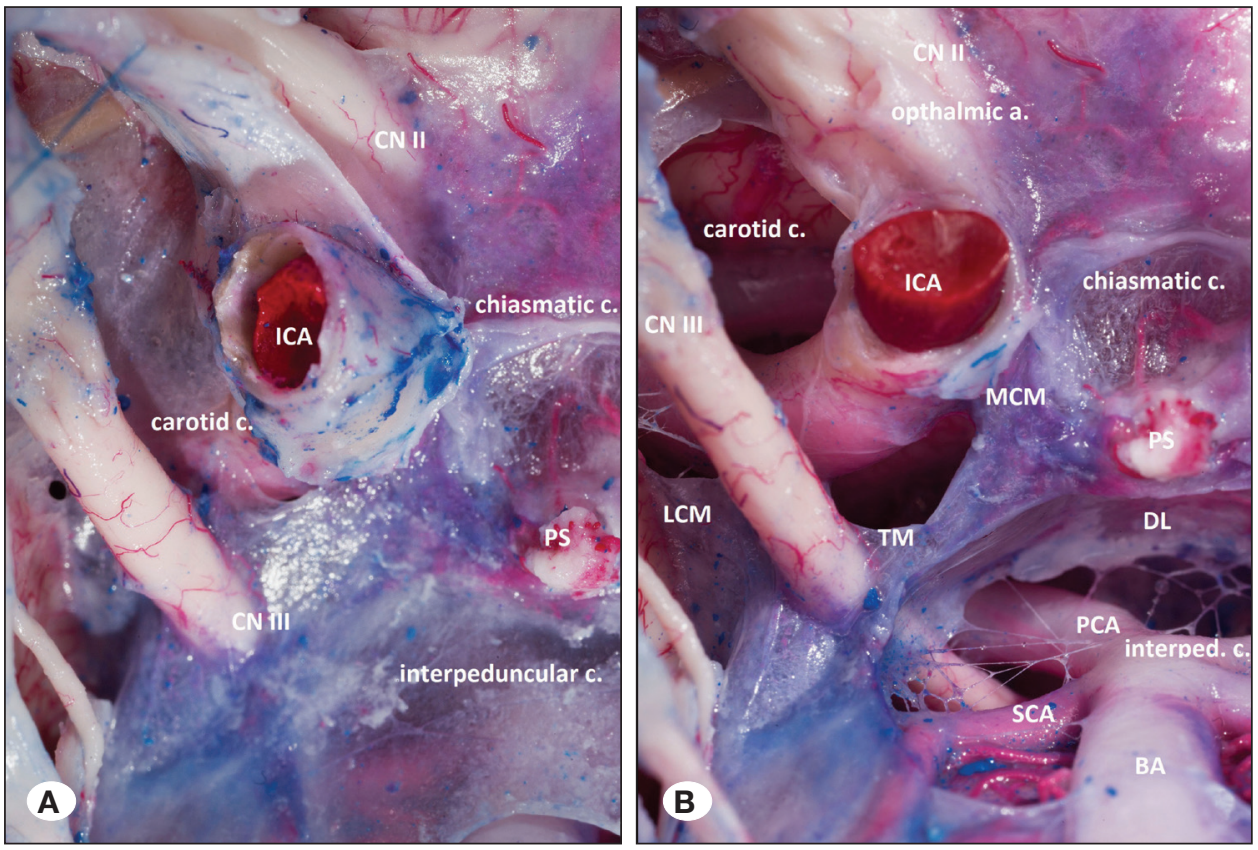

Figure 2: Arachnoid cisterns: chiasmatic, carotid and interpeduncular.

A) Outer arachnoid membrane. CN II: Optic nerve, CN III: oculomotor nerve, ICA: internal carotid artery, PS: pituitary stalk.

B) Inner arachnoid membranes.

CN II: optic nerve, CN III: oculomotor nerve, ICA: internal carotid artery,

BA: basilar artery, PCA: posterior cerebral artery, SCA: superior cerebellar artery, MCM, medial carotid membrane; DL: diencephalic leaf of the Liliequist's membrane, TM: temporal membrane,

LCM: lateral carotid membrane, PS: pituitary stalk. 


\section{Arachnoid Studies}

Since the arachnoid was discovered by the Dutch anatomist Gerardus Blasius in 1664, many techniques have been proposed to study its anatomy (21). In the modern era Yasargil was the first to use the operative microscope for the arachnoid studies, emphasising the importance of the arachnoid cisterns in a clinical context $(13,25,26)$. The first detailed study of the posterior fossa subarachnoid space was published by Matsuno and Rhoton in 1988 (17). The first endoscopic study was published in 2009 by Innoue et al. (9).

Visualisation of the outer and inner arachnoid membranes using the HPHP technique is showed in Figure 2. We believe that high-quality anatomical studies could be performed using this method. However, an extremely gentle manipulation is crucial to preserve the arachnoid structure. Another pitfall of this technique is arachnoid damage caused by latex leak that occurs most commonly from tiny veins of posterior fossa in approximately one of three specimens.

The arachnoid studies belong to the most difficult ones. During specimen preparation, its translucent colour could be stained by minor latex leak. During dissection, even the slightest manipulation leads to its damage. And finally the descriptions of its topographic anatomy is difficult because of high interindividual variability. As a result, the combination of microscopic and endoscopic observation is suggested. The microscopic study using the newly described method provides a general view of the arachnoid cisterns and could be a complementary method to endoscopic studies that ensure more detailed views.

\section{Comparison of Methods Applied in Arachnoid Studies}

Over the years, variable methods were proposed for arachnoid observation. The basic concepts are surgical observation, imaging, and cadaver studies.

Surgery alone allows for in vivo arachnoid observation. The modern era of arachnoid observation began when Yasargil published the first comprehensive description of arachnoid anatomy based on extensive observations using optic magnification during the 4200 intracranial interventions $(25,26)$. Advantages of surgical observation are intact arachnoid structure in physiological conditions (absence of lytic process). In contrast, in most cases the pathology altering anatomy (eg.tumor, aneurysm) is present, the surgical exposure is limited and the time for observation as well.

The neuroimaging studies of sufficient resolution would be a perfect technique for in vivo non-invasive observation. In 1998 Buxton et al. used T2-weighted magnetic resonance imaging (MRI) to visualize the Liliequist's membrane (4). The threedimensional constructive interference in the steady-state (3D-CISS) sequence of MRI was used by Fushimi et al. and recently by Ciappetta et al. $(5,8)$. This sequence enables the visualization of the fine structures within the cerebrospinal fluid $(7,8)$. Unfortunately, the resolution of the present MRI studies is insufficient to display all the fine arachnoid structures $(4,7,8)$.
Cadaver studies allow for extensive arachnoid observation. Macroscopic observation ensures the general overview and observation using optic magnification with operative microscopes $(11,12,17)$ or endoscopes $(2,9,27)$ provide detailed views. As promoted by some authors major advantage of the fresh cadaver specimens is the minimal arachnoid damage caused by the lytic process (5). In contrast, the lytic process damage the non-fixed cadaver during dissection, the vessels are not injected and some law restrictions could be encountered. Formalin-fixed specimens allow for sequential work on well-fixed specimens. We prevent the lytic processes by immediate formalin vessel perfusion followed by latex injection. Moreover, small craniotomies at the convexity, allowing for entrance of formalin solution, accelerate the process of fixation, meanwhile, the specimen is kept at $4^{\circ} \mathrm{C}$. In these specimens, the observation is performed: 1. through surgical approaches, 2 . on the extracted brains, or 3 . following removal of the entire skull base. Defined keyhole approaches were applied by Kurucz et al. who performed endoscopeassisted or endoscope-controlled microsurgical observation. This technique is quick and gentle to arachnoid, however, the exposures are limited by narrow anatomical corridors $(11,12)$. The brain extraction while keeping the arachnoid intact is extremely difficult $(9,23,24)$. All the neurovascular structures traversing the skull need to be delicately interrupted and frequently arachnoid damage is inevitable. On contrary, the skull base removal leaving skull base dura mater intact is safe but time-consuming. This approach was promoted, among the others, by Lu et al. The major difficulty underlined by Lu et al. was the adherence of the skull base with the dura mater. Some adherent parts of bone had to be retained in order not to damage the underlying structures (14-16). Our technique softens the skull base and makes it less adherent to the dura mater, thus the bone could be removed easily by Kerrison or speed drill. During the removal, the dura mater protects the outer and inner arachnoid membranes.

For summary, our dissection method on formalin-fixed cadaveres allow for in-depth arachnoid observation, the vessel injection by latex enhances the vasculature and the skull base softening reduces the drilling time and release the adherences between the dura and the arachnoid. The result is inferior view of all the skull base cisterns with its content and anatomical relationships.

\section{CONCLUSION}

The HPHP technique allows the acquisition of high-quality skull base specimens in which skull base drilling is facilitated by bone softening. The singularity of this method is the uncommon downside-up view of anatomical observation. As a consequence, the topographic anatomy not evident with casual methods could be observed. We suggestits future implications in: 1) neurosurgical training to study complex skull base topographic anatomy and especially for learning the extradural approaches 2) as a complementary method to perform high-quality arachnoid studies.

Supported by: NV19-04-00272, MO 1012, Q25 


\section{REFERENCES}

1. Abrantes AA, Rafacho A, Rivero ER, Mariano FV, Siqueira FM, Gondak RO: Tissue integrity, costs and time associated with different agents for histological bone preparation. Microsc Res Tech 80:344-349, 2017

2. Anik I, Ceylan S, Koc K, Tugasaygi M, Sirin G, Gazioglu N, Sam B: Microsurgical and endoscopic anatomy of Liliequist's membrane and the prepontine membranes: Cadaveric study and clinical implications. Acta Neurochir (Wien) 153:17011711, 2011

3. Bernard F, Terrier LM, Michalak S, Velut S: Hydrogen Peroxide Head Preparation: Enabling cuttings and anatomic studies of skull base dura mater and arachnoid without use of drilling. World Neurosurg 119:325-330, 2018

4. Buxton N, Vloeberghs M, Punt J: Liliequist's membrane in minimally invasive endoscopic neurosurgery. Clin Anat 11:187-190, 1998

5. Ciappetta P, Pescatori L: Anatomic dissection of arachnoid membranes encircling the pituitary stalk on fresh, nonformalin-fixed specimens: Anatomoradiologic correlations and clinical applications in craniopharyngioma surgery. World Neurosurg 108:479-490, 2017

6. Froelich SC, Aziz KM, Levine NB, Theodosopoulos PV, van Loveren HR, Keller JT: Refinement of the extradural anterior clinoidectomy: Surgical anatomy of the orbitotemporal periosteal fold. Neurosurgery 61:179-185; discussion 185176, 2007

7. Fushimi Y, Miki Y, Takahashi JA, Kikuta K, Hashimoto N, Hanakawa T, Fukuyama H, Togashi K: MR imaging of Liliequist's membrane. Radiat Med 24:85-90, 2006

8. Fushimi Y, Miki Y, Ueba T, Kanagaki M, Takahashi T, Yamamoto A, Haque TL, Konishi J, Takahashi JA, Hashimoto N, Konishi $\mathrm{J}$ : Liliequist membrane: Three-dimensional constructive interference in steady state MR imaging. Radiology 229:360365; discussion 365, 2003

9. Inoue K, Seker A, Osawa S, Alencastro LF, Matsushima T, Rhoton AL Jr: Microsurgical and endoscopic anatomy of the supratentorial arachnoidal membranes and cisterns. Neurosurgery 65:644-664; discussion 665, 2009

10. Kim JS, Lee SI, Jeon KD, Choi BS: The pterional approach and extradural anterior clinoidectomy to clip paraclinoid aneurysms. J Cerebrovasc Endovasc Neurosurg 15:260-266, 2013

11. Kurucz P, Baksa G, Patonay L, Hopf JN: Endoscopic anatomical study of the arachnoid architecture on the base of the skull. Part I: The anterior and middle cranial fossa Innovative Neurosurgery 1:55-66, 2013
12. Kurucz P, Baksa G, Patonay L, Hopf JN: Endoscopic anatomical study of the arachnoid architecture on the base of the skull. Part II: Level of the tentorium, posterior fossa and the craniovertebral junction. Innovative Neurosurgery 1:91108, 2013

13. Lü J: Arachnoid membrane: The first and probably the last piece of the roadmap. Surg Radiol Anat 37:127-138, 2015

14. Lü J, Zhu X: Microsurgical anatomy of the interpeduncular cistern and related arachnoid membranes. I Neurosurg 103:337-341, 2005

15. Lü J, Zhu XI: Microsurgical anatomy of Liliequist's membrane. Minim Invasive Neurosurg 46:149-154, 2003

16. Lü J, Zhu XL: Cranial arachnoid membranes: Some aspects of microsurgical anatomy. Clin Anat 20:502-511, 2007

17. Matsuno H, Rhoton AL Jr, Peace D: Microsurgical anatomy of the posterior fossa cisterns. Neurosurgery 23:58-80, 1988

18. Noguchi A, Balasingam V, Shiokawa Y, McMenomey SO, Delashaw JB Jr: Extradural anterior clinoidectomy. Technical note. J Neurosurg 102:945-950, 2005

19. Prasad P, Donoghue M: A comparative study of various decalcification techniques. Indian J Dent Res 24:302-308, 2013

20. Rhoton AL Jr: The cavernous sinus, the cavernous venous plexus, and the carotid collar. Neurosurgery 51:S375-410, 2002

21. Sanan A, van Loveren HR: The arachnoid and the myth of Arachne. Neurosurgery 45:152-155; discussion 155-157, 1999

22. Tayebi Meybodi A, Lawton MT, Yousef S, Guo X, Gonzalez Sanchez JJ, Tabani H, Garcia S, Burkhardt JK, Benet A: Anterior clinoidectomy using an extradural and intradural 2-step hybrid technique. J Neurosurg 130:238-247, 2018

23. Vinas FC, Dujovny M, Fandino R, Chavez V: Microsurgical anatomy of the arachnoidal trabecular membranes and cisterns at the level of the tentorium. Neurol Res 18:305-312, 1996

24. Vinas FC, Dujovny M, Fandino R, Chavez V: Microsurgical anatomy of the infratentorial trabecular membranes and subarachnoid cisterns. Neurol Res 18:117-125, 1996

25. Yasargil MG: Microneurosurgery. I Georg (ed), Stuttgart: Thieme, 1984

26. Yasargil MG, Kasdaglis K, Jain KK, Weber HP: Anatomical observations of the subarachnoid cisterns of the brain during surgery. J Neurosurg 44:298-302, 1976

27. Zhang XA, Qi ST, Huang GL, Long H, Fan J, Peng JX: Anatomical and histological study of Liliequist's membrane: With emphasis on its nature and lateral attachments. Childs Nerv Syst 28:65-72, 2012 